\title{
The use of towed camera platforms in deep-water science
}

Daniel O. B. Jones*, Brian J. Bett, Russell B. Wynn and Douglas G. Masson

National Oceanography Centre, Southampton, SO14 3ZH, UK

* Corresponding author (dj1@noc.soton.ac.uk)

\section{ABSTRACT}

Towed camera platforms have been important in the study of the deep sea for over 30 years. The use of towed camera platforms in deep-water science is reviewed, drawing from the experiences of the National Oceanography Centre, Southampton's towed cameras, the Wide Angle Seabed Photography (WASP) vehicle and the Seafloor High Resolution Imaging Platform (SHRIMP). Practical considerations for towed camera platform use are outlined with particular reference to sensors, flying altitude and comparison between photographs and video. Although the technology for towed camera platforms will change over time, the concept remains of great value in studying the remote deep-sea environment.

\section{INTRODUCTION}

Seabed imaging technology has been in scientific use for several decades (Hersey, 1967; Heezen and Hollister, 1971). Deep-water photography is a long established technique for the investigation of benthic environments. Practically, a single 
photograph of the seafloor, for use in biological investigation, can cover approximately $1-10 \mathrm{~m}^{2}$ of seafloor. For geological studies potentially larger areas can be covered. In biological investigations it is most practical to measure resolution as the minimum size of repeatedly identifiable organisms, referred to subsequently as 'biological resolution'. Values as low as $1 \mathrm{~mm}$ have been reported for a $70 \mathrm{~mm}$ medium format camera operated on a bounce camera system (Gutt and Starmans, 1998). These systems tend to photograph only a small area of the seafloor $\left(1.4 \mathrm{~m}^{2}\right.$ in the system used by Gutt and Starmans 1998). An alternative strategy, as adopted by towed camera platforms, is to photograph much greater areas of the seafloor at a lower resolution. Typically these systems have a biological resolution of around 10-50 $\mathrm{mm}$. There is generally a trade-off between spatial extent of a survey, film or memory requirements, duration of survey and biological resolution.

Towed camera platforms provide a deep-water equivalent of aerial photography although at a smaller spatial scale taking into account the greatly increased attenuation of the visible light spectrum in water compared to air. Towed camera platforms are used routinely in the investigation of deep-water biology (Machan and Fedra, 1975; Hashimoto and Hotta, 1985; Christiansen and Thiel, 1992; Hecker, 1994; Bett et al., 1995; Barker et al., 1999; Cailliet et al., 1999; Bett, 2001; Kollmann and Stachowitsch, 2001; Cranmer et al., 2003; Mortensen and Buhl-Mortensen, 2004) and geology (Hecker, 1990; Kleinrock et al., 1992; Leybourne and Vanwagoner, 1992; Barker et al., 1999; McHugh and Ryan, 2000; Masson, 2001; Wynn et al., 2002; Fornari, 2003), often for the initial assessment of the seabed character before more detailed investigations take place, such as in hydrothermal vent research or in the 
search for archaeological artefacts (Lonsdale, 1977a; Lonsdale, 1977b; McConachy et al., 1986; Ballard et al., 2000; Singh et al., 2000; Klinkhammer et al., 2001).

Towed camera platforms have been used in deep-water studies covering a range of scales from the whole region, to mid-scale descriptions of the geology and biology of a seabed feature to the fine scale of patterns in biology and geology within a specific habitat. At a regional scale Masson (2001) mapped much of the area of the FaroeShetland Channel, NE Atlantic Ocean, using deep-towed side-scan sonar (30 kHz). This technique allowed the separation of major habitat types in the area, however it was not possible to directly and reliably relate the acoustic returns to known habitat types. A towed camera platform (WASP) was used for visual investigation of these pre-determined areas to assess local sedimentology and geology. The ground-truthing of the side-scan data, by using representative towed camera platform transects, allowed the results of the seabed photography to be extrapolated to much wider areas than it was possible to image directly (Masson, 2001). In addition, examination of sediment bedforms and organism morphology in photographs was used, in conjunction with published information on current velocities associated with the various features (Heezen and Hollister, 1971; Normark et al., 1980; Werner et al., 1980), to reliably reconstruct the pattern of bottom currents acting on the channel floor (Masson, 2001).

Variation across individual geomorphological features has been investigated with a finer-scale towed camera platform study. A combination of high-resolution side-scan sonar and WASP photography was used to image barchan dunes (120 m horn-to-horn width) and sand ripples in the Faroe-Shetland Channel (Wynn et al., 2002). An 
acoustic transponder provided ultra-short baseline navigational data referenced to the ship's differential-GPS position. This detailed navigational information enabled accurate (to $<10 \mathrm{~m}$ ) georeferencing of photographic and acoustic images. Seabed sediment features were used to show how patterns of current flow changed across the barchan in response to dune morphology (Wynn et al., 2002).

Towed camera platforms carrying multiple imagers can be used for multi-scale assessment of benthic features especially in conjunction with acoustic data. Jones et al., (2007b) investigated the effects of disturbance by icebergs on the benthic megafauna of the north eastern Weddell Sea using the WASP towed camera. Disturbance was investigated at three scales using different methods: swath bathymetry was used to identify iceberg plough features at a broad scale (extent 20$1,000 \mathrm{~m}$, grain resolution $5 \mathrm{~m}$ ), continuous video used to identify the mid-scale patterns of visible effects of iceberg ploughing, such as patterns in sediment distribution and clear topographic differences from mechanical disturbance at plough edges (extent 5-20 m, grain resolution $0.1 \mathrm{~m}$ ) and still photography to identify biological patterns associated with iceberg ploughing (extent 0.05-5 m, grain resolution $0.05 \mathrm{~m})$.

Many studies have used towed camera platform photographs to characterise fine-scale patterns in biological communities (Thurston et al., 1994; Jones et al., 2007c; Jones et al., 2007a) and through sampling a number of areas, attempted to extrapolate these to wider areas. Most studies use direct faunal counts (Hecker, 1994; Ruhl, 2007) although some studies have also used inferred biological activity from faunal traces or Lebensspuren (Ewing and Davis, 1967; Jones et al., 2007c). 
It is very important that, in scientific studies, the methods are carefully assessed, in relation to the strengths and limitations of the data they provide. Using results from extensive towed camera investigations carried out by the National Oceanography Centre, Southampton (formerly Southampton Oceanography Centre), results and some considerations for the use of towed camera platforms are presented.

\section{THE WIDE ANGLE SEABED PHOTOGRAPHY SYSTEM: AN EXAMPLE TOWED CAMERA SYSTEM}

The National Oceanography Centre, Southampton Wide Angle Seabed Photography (WASP) system is a simple but effective example of a towed camera platform. WASP

(Figure 1) is a self-contained, off-bottom, towed camera platform that provides still and video footage of the seabed, and is capable of operation to $6,000 \mathrm{~m}$ water depth on a simple mechanical cable (i.e. conducting or fibre-optic cable not required). WASP is fitted with: OSIL Mk7 (stills) camera, OSIL 1200J flash gun, NOC OceanCam6000V (digital video) camera, 2 x 250W DSPL video lamps, 3 x DSPL 24V batteries, Simrad Mesotech $200 \mathrm{kHz}$ altimeter, and a NOC acoustic telemetry system $(10 \mathrm{kHz})$. Data from the altimeter are telemetered to a shipborne display enabling the operator to make fine adjustments of the amount of cable deployed with the aim of keeping the vehicle at c. $3 \mathrm{~m}$ above the seabed. The still and video cameras are both automatically activated by the altimeter when the range to the seabed is $<10$ $\mathrm{m}$. The still camera is typically loaded with a $30 \mathrm{~m}$ length of $35 \mathrm{~mm}$ format Kodak Vision 250D, allowing for over 700 photographs, and the video camera loaded with a 63 minute MiniDV tape. 
The acoustic telemetry from WASP is typically received through the operating ship's towed or hull mounted transducers and monitored with a PC based waterfall display system. It was usually possible to operate WASP at a roughly constant altitude $(2.5 \mathrm{~m}$ $\pm 1 \mathrm{~m})$.

The National Oceanography Centre, Southampton also owns and operates a related towed camera platform, the Seabed High Resolution Imaging Platform (SHRIMP). This is similar to the WASP system except the video signal is transferred via a fibre optic cable to the surface where it is recorded and also used to fly the vehicle at optimal height above the seafloor.

PRACTICAL CONSIDERATIONS FOR TOWED CAMERA PLATFORM STUDIES

Towed camera platforms are used for a variety of applications, both quantitative and qualitative. Many uses are qualitative, often a simple visual assessment of seabed conditions to assess habitat type or dominant species. In some circumstances these observations need to produce high-quality imagery for public display or outreach, in these cases the camera setup may be different to that discussed for quantitative imagery. For outreach purposes an oblique camera angle is often preferred, in some cases non-uniform lighting will emphasize certain elements of the fauna. If equipment allows, it may be best to trigger photograph capture in response to features of interest via a live linkage to the surface, usually a fiber optic cable. 
Quantitative assessment of seabed conditions requires a consistent, planned approach to imagery for optimal results. It is often difficult to accurately quantify imagery obtained without prior assessment of the following factors:

1. The hypothesis to be tested

2. Appropriate survey design (to rigorously test hypotheses)

3. Scaling of imagery (to allow quantification)

4. Optimal imagery for hypothesis under investigation (camera setup and lighting)

5. Additional sensors required (for navigation etc.)

The generation of hypotheses and survey design are very important but generally beyond the scope of this paper and are dealt with in detail elsewhere (Barry and Baxter, 1992; Underwood and Chapman, 1998).

\section{Scaling of imagery}

Scaling of imagery is vital for all quantitative applications of towed camera platform imagery. Practical suggestions are presented here for likely operations of towed camera platforms. We have principally considered calculation of the area of seabed analyzed rather than measurement of features. For more information on feature measurement and other specific applications a wide literature on photogrammetric techniques is available (e.g. Wolf, 1983).

\section{Calculating areal coverage}


There are three main options for calculating the areal coverage of seabed images, 1) trigonometric approach using altitude and optical camera angles, 2) photogrammetric approach using stereo images, and 3) direct scaling using parallel lasers to project a pattern of known dimensions onto the seabed. In other imaging applications scaling can be achieved by placing an object of known size in the field of view; this is not usually possible using towed camera systems as a result of changes in altitude.

Altitude data (i.e. the height of the camera above the seabed) are printed directly onto each photograph for the WASP system allowing the scale of the image to be calculated. For some towed camera systems e.g. SHRIMP, these data are recorded at the surface with a data logger, in this case altitude is obtained by matching time stamps on the photograph with altitude data. Altitude is converted to areal coverage for individual frames using equation 1 , where $\mathrm{a}=$ camera altitude (e.g. meters), $\theta=$ horizontal camera acceptance angle (degrees), $\omega=$ vertical camera acceptance angle (degrees):

\section{Equation 1:}

Area of photograph $=4 a^{2} \tan \left(\frac{\theta}{2}\right) \tan \left(\frac{\omega}{2}\right)$

Only area calculation from vertical images is shown here, the calculation of area from oblique images is discussed in Wakefield and Genin (1987).

When used in transect mode the alongtrack coverage does not necessarily increase.

With greater areal coverage of each photographic frame as altitude increases 
photographs begin to overlap. In transect mode it is desirable to minimise altitude variation. The following examples assume a constant altitude (a) although the technique is approximately applicable where there is a small-amplitude regular sinusoidal movement of the camera (e.g. from swell action on the towing vessel) and mean altitude can be used. Overlap can be calculated from equation 2 , where $\mathrm{v}=$ towed camera platform speed $\left(\mathrm{ms}^{-1}\right), \mathrm{t}=$ time between frames (seconds):

\section{Equation 2:}

Overlap $=\left(2 a \tan \left(\frac{\omega}{2}\right)\right)-(v . t)$

If overlap is negative (i.e. the frames do not overlap) then area can be calculated from the area of one frame (equation 1) multiplied by the number of frames (n).

If overlap is positive the area of the whole transect can be calculated from equation 3 :

\section{Equation 3:}

Area of transect $=4 \cdot a^{2} \tan \left(\frac{\omega}{2}\right) \cdot \tan \left(\frac{\theta}{2}\right)+2 \cdot a \cdot n \cdot v \cdot t \cdot \tan \left(\frac{\theta}{2}\right)-2 \cdot a \cdot v \cdot t \cdot \tan \left(\frac{\theta}{2}\right)$

\section{Laser scaling}

Scaling can be achieved by projecting points, spaced by a known distance, onto the area to be photographed. This is usually achieved using parallel-laser systems, projecting two red or green laser dots a constant distance apart (Tusting and Davis, 
1992; Pilgrim et al., 2000). As the beams are parallel there is no change in dimension with altitude. More advanced systems allow accurate scaling of the image for variations in altitude, pitch, roll and yaw of the vehicle, as well as zoom and position of the camera using a series of lasers. A five-laser system can allow scaling with variations in zoom, camera angle and altitude on a flat horizontal surface. In a fivelaser system four are set out forming the corners of a square, all parallel, and one, outside the square, is non-parallel and pointing into the square. A six-laser system can additionally allow quantification on vertical surfaces. Systems with sixteen lasers are in development allowing the scaling and measurement of certain non-flat surfaces, namely cylinders, spheres and cones (Pilgrim et al., 2000; Shortis et al., 2007).

\section{Stereo camera systems}

Stereo camera systems can also be used successfully for image quantification, including three-dimensional measurement (Abdo et al., 2006). These systems can also accurately measure range and bearing of midwater targets such as fish (Harvey et al., 2003). Trigonometric approaches are used to quantify imagery (Shortis and Harvey, 1998); these are very sensitive to changes in camera setup and hence cameras are mounted and calibrated before imaging. Sensitivity to changes in focus and aperture should be considered if using these systems on towed camera systems with highly variable altitude.

\section{Quantification from video}


Quantification of imagery from video can be achieved using three main methods: extraction of still frames, complete counts and video mosaicing. The scaling methods outlined above can also be used with video. Specific methods for quantification of video for analysis are dealt with here.

The most common method in shallow waters, particularly in the study of hard substrata such as coral reefs, is extracting single frames at random from the video for analysis (Meier and Porter, 1991), effectively leaving the operator with still photographs to be analysed. In practice, analysis is often achieved using commercial software such as coral point count (Kohler and Gill, 2006). Once a still frame has been extracted methodologies for analysis are identical to those for still photographs. The still frame extraction method has a number of advantages, including speed of analysis and in calculating percentage cover of high-cover environments, however a huge amount of information contained in the video is lost. An additional disadvantage is that the quality of still frames extracted from video is of a considerably lower resolution than that obtained from dedicated photographic imagers. With recent advances in video technology this is less of a problem, as a high-definition video and high-quality recording medium (e.g. DVCam) will produce still frames of almost photographic quality.

Complete count methods have the advantage of making full use of the information in the video, all objects of interest are counted in the video as it proceeds across the seabed. In towed camera platform video, objects are typically counted as they pass a line perpendicular to the direction of travel (Jones et al., 2006). In oblique video (and the camera facing along the imaging path) the base of the screen is the clearest part of 
the image for analysis. The operator can calculate the length on the seabed of the line at the base of the image using equation 4 , where $\mathrm{a}=$ camera altitude (e.g. meters), $\theta=$ horizontal camera acceptance angle (degrees), $\omega=$ vertical camera acceptance angle (degrees) and $\delta=$ angle of the camera from vertical (degrees):

\section{Equation 4:}

Length of base of screen $=2 \sin (0.5 \theta) \sqrt{\alpha \sin (90-\delta-0.5 \omega)^{2}+\alpha^{2}}$

The seabed covered by the back edges of the oblique image are ignored in this method, in practice these are usually the lowest resolution and least well lit areas of the image. The track length can be calculated using positioning information on the towed camera platform (e.g. ultra-short or long baseline navigation), or approximated from the change in ship's position over the run length. The total areal coverage of the track analysed in this way can be approximated by the average width multiplied by the track length. This method of analysis is well suited to the majority of deep-water settings where sediment tends to be fine, coverage is low and individual objects tend to contrast with the substratum.

Recent advances in imaging are permitting large areas of seabed to be mosaiced from either video or still images (Pizarro and Singh, 2003). Mosaicing of video represents an alternative method for object quantification. With suitable mosaicing algorithms the entire area of seabed covered by the imager will be used in analysis. This method also has the advantage of being able to see large-scale patterns not visible in an individual photograph or a single point in time in a video. If mosaicing is desired it is very important to set up the imager for this with a vertical orientation and no header 
information printed onto the image. It is also beneficial if constant altitude, pitch, roll, yaw, lighting and speed are maintained (Pizarro and Singh, 2003).

With suitable positioning equipment (e.g. long-baseline transponders) all of these methods allow accurate georeferencing of objects in the video. This can be used to enhance the accuracy of track length, to map the position of objects imaged for subsequent analysis, or for integration into geographic information system databases.

\section{Optimal imagery}

With such a wide range of options for imager, imager set-up and towed body operation, it is important to present practical comparisons in the important parameters to ensure that the method can be optimised for each specific application. The following section concentrates on biological analysis as the objects of interest (e.g. animals) in these studies are often small and cryptic, making detection difficult and requiring optimal techniques.

\section{The effects of towed camera platform flying altitude on biological analysis of photographs}

Using photographs taken in water depths of 1000 to $1105 \mathrm{~m}$ in the Faroe-Shetland Channel (Jones et al., 2007c), the effect of altitude on mean density of fauna observed was analysed. For this purpose it was assumed that true faunal density was approximately constant and that organisms were randomly distributed. 
In this example it was expected that the mean number of individuals per photograph was proportional to the actual density of organisms in the area and the area photographed. With WASP camera acceptance angles the area photographed was calculated by equation 5 .

\section{Equation 5:}

Area photographed by WASP $=0.6$ altitude $^{2}$

Altitude was very important in photographic investigations. In the WASP investigation tested here, at both high and low camera altitudes there were large departures of observed individuals from expected (Figure 3). Low altitude conditions resulted in the greatest enumeration of organisms, although it was not consistently possible to fly the WASP vehicle at altitudes below $1.5 \mathrm{~m}$. At high altitudes, while the areal coverage was great, there were significantly lower numbers of visible fauna. Photographs taken between 1.5 and $3.5 \mathrm{~m}$ altitude revealed consistent average numbers of organisms as well as providing a reasonable range of altitudes for effective operation of the WASP vehicle and hence a reasonable number of photographs for analysis.

The reduction in faunal numbers observed with increasing altitude was a direct result of the limitations in the underwater camera system. As light dissipates through water much faster than through air; underwater photography over a distance of greater than several meters is challenging. Both absorption by seawater and scattering by suspended particulate matter rapidly reduce light intensity. Additionally, the increased distance results in decreased film grains per area of seabed and hence lower biological 
resolution of photographs, making it difficult to distinguish organisms from a heterogeneous substratum.

At low camera altitude there was a departure of observed individuals from expected and an increase in variability of the data. This appears to be a result of greater detection of fauna in higher biological resolution photographs and the increasing influence of stochastic distributions of megafauna with small imaging area. It was not possible to 'fly' the towed camera platform consistently at altitudes of $1.5 \mathrm{~m}$ or less, owing to ship movements and variations in the topography of the areas investigated.

The biological conclusions were that when using faunal density values obtained from a platform with variable altitude, caution should be exercised as to the altitude of the vehicle. The optimal altitude depends on the minimum size of fauna that needs to be resolved and the minimum operational altitude of the vehicle. In practical terms for this study, with a minimum faunal resolution of $50 \mathrm{~mm}$, estimates of faunal density from WASP photographs are likely to be very much reduced from true values at altitudes greater than $3.5 \mathrm{~m}$. Only the larger and more conspicuous fauna will be seen at altitudes greater than $3.5 \mathrm{~m}$.

The altitude at which photographs were taken affects the biological resolution of the photographs, which has been shown here to affect the measured density and diversity of the communities under investigation. However increases in altitude result in sampling an increasing area of seabed, particularly important as the area sampled increases proportionally to the square of the altitude. 


\section{The effects of towed camera platform flying altitude on scientific analysis of video}

For quantitative analysis of video, with its inherently lower resolution, the effects of camera altitude are particularly important. An illustration of this can be obtained from a study in the Faroe-Shetland Channel, UK (420-421 m depth, $60^{\circ} 22.95^{\prime} \mathrm{N}$ $\left.04^{\circ} 05.95^{\prime} \mathrm{W}\right)$. Two video transects were conducted along a small diameter pipeline, and observations of fauna at two altitudes ( 1 and 3 metres) were made with a standard wide-angle lens between two conspicuous markings spaced $50 \mathrm{~m}$ apart on the pipe.

In video observations at $3 \mathrm{~m}$ altitude 3 times the areal extent of seabed was investigated to that at $1 \mathrm{~m}$ altitude. However, only one taxon, a brilliant white sponge, could be identified at $3 \mathrm{~m}$ altitude, in addition, densities of this species were less than a quarter of those identified from the $1 \mathrm{~m}$ altitude transect $\left(2.51\right.$ individuals $\mathrm{m}^{-2}$ at 1 $\mathrm{m} ; 0.37$ at $3 \mathrm{~m}$ ). Overall densities were clearly much reduced in the high altitude video.

It is important in towed camera platform studies to minimise the altitude of sampling to identify as many megafaunal organisms as possible. It has been shown here that video investigations of megafauna should not be conducted at high altitude unless a zooming lens is used $(>2 \mathrm{~m})$. However video at this altitude can still be useful for characterisation of geological features, and in conjunction with photographs to provide information on the seafloor environment at a landscape scale. Video and lens quality, lighting and platform speed are all important to optimize for quantitative video work. 


\section{Comparisons between photographs and video for scientific analysis}

There is relatively widespread use of both video and photographs in marine ecology (Solan et al., 2002). The best technique depends upon the hypothesis under investigation and the imaging platform. Very successful high image resolution video has been obtained using ROVs as imaging platforms (Starmans et al., 1999). However, with towed camera platforms, video is often used to get an impression of the spatial variation in an area, whereas, for quantification of faunal patterns still photography is generally used (Jones et al., 2007c). Using a towed camera platform that collects video and photographic data simultaneously (WASP), it was possible to compare the biological outcomes for the two techniques directly. This was carried out for an example station (FSC 1) in the Faroe-Shetland Channel (Jones et al., 2007c). Despite the greater areal coverage of video as a result of continuous recording $(183 \%$ coverage of photographs), there were large reductions in apparent faunal densities (by $38 \%$ relative to photographic densities) and all diversity measures when compared with photographic assessment of the same community (Table 1). These differences resulted from the significantly lower resolution of imagery in the video.

\section{The sampling unit}

The properties of light in water determine the practical size of the photograph. This does not necessarily provide a good reason to use a single photograph as the sampling unit, particularly with changes in sample unit size associated with use of towed camera platforms (Table 2). In many biological studies in deep water single 
photographs are likely to be an inappropriate sampling unit owing to the scarcity of fauna. Pooling photographs, either a specific number of photographs or better photographs that cover a specific area, is often a useful approach for some analyses (particularly diversity / density) which has been used in some studies (Jones et al., 2007c; Jones et al., 2007a; Jones et al., 2007b). Deciding on the sampling unit is an important step in most ecological studies (Sokal and Rohlf, 1995; Lenth, 2001) which is often ignored in photographic studies.

\section{Camera and strobe setup}

In deep-water studies, owing to the lack of ambient light (Gage and Tyler, 1991), a high-powered light-source is vital for successful imagery. High powered video lights may not be suitable for still photography and a separate strobe may also be necessary (as found for WASP and SHRIMP). The relative position of camera and light source on the towed camera platform are important. Backscatter from suspended particulates can be minimized by maximal separation between camera and light source. Separating the light source from the camera system has the additional benefit of highlighting relief and allowing quantification of vertical relief through shadows (Hersey, 1967).

The majority of moving-platform imaging devices have camera focus pre-set and fixed for the duration of the imaging run depending on the target altitude. One of the performance limiting factors for use of such an imaging arrangement is the depth of field (DOF) required. A trade off must be made between the DOF and amount of light entering the imager, as a large DOF required a small aperture (high $\mathrm{f}$ number). Infocus images are required for a set range of vehicle flying altitude. The field of view 
for a camera system, with focal length: $f$, numerical aperture: $\mathrm{N}$, acceptable circle of confusion: c, range to object: $\mathrm{R}$, is shown in equation 6 .

\section{Equation 6:}

$\mathrm{DOF}=\frac{2 \cdot f^{2} \cdot R \cdot c \cdot(f-R)}{\left(R \cdot N \cdot c-f \cdot N \cdot c-f^{2}\right) \cdot\left(R \cdot N \cdot c-f \cdot N \cdot c+f^{2}\right)}$

The camera aperture is set to maximise depth of field yet retain sufficient light for correct exposure. Shutter speed is less of a consideration in deep-sea settings as ambient light is negligible, the strobe power and duration can control exposure of the image. A nominal 1/60 second exposure is used in WASP, although tests on the strobe with a photodiode indicated that $50 \%$ of the energy was output within 1 millisecond. Excessively slow shutter speeds are unnecessary, especially if video lamps are also used for lighting as image smearing can occur.

\section{Sensor considerations}

The medium for photographic recording is also important in deep-water photography. Traditionally $35 \mathrm{~mm}$ film is used (Hersey, 1967), which provides a reasonably high image resolution and, as a standard format, relatively low cost. Conventional film has some disadvantages, for example it occupies reasonably large physical spaces, particularly in the volumes needed for seafloor survey, and processing usually cannot be done at sea and so image quality and faunal patterns cannot be assessed quickly at a time scale relevant to further sampling. Post-processing of the film for analysis, such as scanning, can also take longer. The resolution of $35 \mathrm{~mm}$ film conventionally 
used in deep-water photography (ISO 250 film) is approximately equivalent, in terms of silver crystal density, to a digital resolution of around 10 megapixels, although noise in digital cameras is much lower than grain (its counterpart) in film. Digital camera systems are being increasingly used in deep-water photography (see e.g. Fornari, 2003); these systems may have reduced resolution over film but have a number of important advantages: immediate results, low operational cost, virtually unlimited storage and native digital format facilitating presentation and analysis. Computer-aided analysis techniques for digital photographs include digital image analysis (for quantification of sizes and areas) and potentially more advanced photogrammetric techniques. Computer aided analysis techniques are possible by scanning film photographs, however this is costly and time consuming for the volume of photographs required for high quality analyses.

There are several options for camera mounting used in deep-water photography pertaining to the angle of the camera from vertical. A vertical camera angle facilitates scaling and subsequent measurement, as well as maintaining relative size of fauna. Oblique angles provide a greater coverage for a given height as well as a more natural view of the seabed, facilitating identification and observation of fauna; scaling, while possible becomes difficult and perspective effects change relative sizes of fauna depending on their position in the frame (Wakefield and Genin, 1987). If photo mosaicing is used a vertical camera angle is necessary. Oblique imaging has important uses in geology as subtle changes in seafloor topography are much more easily detected. Both methods have been used successfully in deep-water photography (Hersey, 1967). 
Underwater video allows a wide swathe of benthos to be recorded quickly with complete coverage. Video resolution is often low, practically around 500 x 500 effective 'pixels' (phosphor dots). This figure applies to blacks, greys and whites only; colour resolution is much less, most often between $25 \times 25$ and 50x50 (NTSC Broadcast, VHS, S-VHS, Hi-8). Video resolution is continually improving, and stateof-the-art high-definition digital video (HD) presently recording 1080x1280 effective 'pixels'. There are needs for improved data transmission and storage technologies to record these high definition images effectively. Most existing science video systems, including WASP, use lower quality systems, however several science-class ROVs have HD video cameras and tape or hard drive based recording equipment.

\section{CONCLUSIONS}

Photographic analysis is a technique that is sure to increase in use into the future, with increasing acceptance as a quantitative tool that has minimal environmental impact. Its limitations are widely understood and are comparable with those of other techniques e.g. semi-quantitative nature of trawls. Photographs provide a minimum quantitative sample of a known part of the faunal community in a similar manner to a sieve sample of macrofauna. Towed camera platform systems represent a relatively cheap and reliable method of undertaking photographic investigations in the deep sea.

\section{ACKNOWLEDGEMENTS}

The work was carried out as part of the DIEPS (Deep-water Industry, Environment, Policy and Science) and HERMES (Hotspot Ecosystem Research on the Margins of 
European Seas) projects. D. Jones was funded by NERC studentship NER/S/A/2002/10397 and DIEPS grant NE/C508518/1. The HERMES project is funded by the European Commission's Framework Six Programme, under the priority Sustainable Development, Global Change and Ecosystems. Contract No. GOCE-CT2005-511234-1. Thanks to the participants of the CenSeam Workshop on image analysis held in Dartington Hall, Plymouth in May 2007 for detailed discussion of many of the ideas presented here. Thanks to Dr David Bowden for valuable comments regarding the manuscript. 


\section{REFERENCES}

Abdo, D.A., Seager, J.W., Harvey, E.S., McDonald, J.I., Kendrick, G.A. \& Shortis, M.R. (2006) Efficiently measuring complex sessile epibenthic organisms using a novel photogrammetric technique. Journal of Experimental Marine Biology and Ecology 339: 120-133

Ballard, R.D., McCann, A.M., Yoerger, D., Whitcomb, L., Mindell, D., Oleson, J., Singh, H., Foley, B., Adams, J., Piechota, D. \& Giangrande, C. (2000) The discovery of ancient history in the deep sea using advanced deep submergence technology. Deep Sea Research Part I: Oceanographic Research Papers 47: 1591-1620

Barker, B.A.J., Helmond, I., J. Bax, N., Williams, A., Davenport, S. \& Wadley, V.A. (1999) A vessel-towed camera platform for surveying seafloor habitats of the continental shelf. Continental Shelf Research 19: 1161-1170

Barry, J.P. \& Baxter, C.H. (1992) Survey Design Considerations for Deep-Sea Benthic Communities Using ROVs. Marine Technology Society Journal 26: 21-26

Bett, B.J. (2001) UK Atlantic Margin Environmental Survey: introduction and overview of bathyal benthic ecology. Continental Shelf Research 21: 917-956

Bett, B.J., Rice, A.L. \& Thurston, M.H. (1995) A quantitative photographic survey of "spoke-burrow" type Lebensspuren on the Cape Verde Abyssal Plain. Internationale Revue der gesamten Hydrobiologie 80: 153-170

Cailliet, G.M., Andrews, A.H., Wakefield, W.W., Moreno, G. \& Rhodes, K.L. (1999) Fish faunal and habitat analyses using trawls, camera sleds and submersibles in benthic deep-sea habitats off central California. Oceanologica Acta 22: 579592

Christiansen, B. \& Thiel, H. (1992) Deep-sea epibenthic megafauna of the Northeast Atlantic: Abundance and biomass at three mid-oceanic locations estimated from photographic transects. In: Rowe, G.T., Pariente, V. (eds) Deep-sea Food Chains and the Global Carbon Cycle. Kluwer Academic Publishers, Dordrecht (Netherlands), pp 125-138

Cranmer, T.L., Ruhl, H.A., Baldwin, R.J. \& Kaufmann, R.S. (2003) Spatial and temporal variation in the abundance, distribution and population structure of epibenthic megafauna in Port Foster, Deception Island. Deep-Sea Research Part II: Topical Studies in Oceanography 50: 1821-1842

Ewing, M. \& Davis, R.A. (1967) Lebensspuren photographed on the ocean floor. In: Hersey, J.B. (ed) Deep-Sea Photography. John Hopkins Press, Baltimore, pp 256-294

Fornari, D.J. (2003) A new deep-sea towed digital camera and multi-rock coring system. EOS, Transactions, American Geophysical Union 84: 69-76

Gage, J.D. \& Tyler, P.A. (1991) Deep Sea Biology. Cambridge University Press, Cambridge

Gutt, J. \& Starmans, A. (1998) Structure and biodiversity of megabenthos in the Weddell and Lazarev Seas (Antarctica): Ecological role of physical parameters and biological interactions. Polar Biology 20: 229-247

Harvey, E.S., Shortis, M.R., Stadler, M. \& Cappo, M. (2003) A comparison of the accuracy of measurements from single and stereo-video systems. Marine Technology Society Journal 36: 38-49 
Hashimoto, J. \& Hotta, H. (1985) An attempt of density estimation of megaloepibenthos by a deep towed TV system and the deep sea research submersible Shinkai 2000. Technical Reports of the Japan Marine Science and Technology Center: 23-36

Hecker, B. (1990) Photographic Evidence for the Rapid Flux of Particles to the SeaFloor and Their Transport Down the Continental-Slope. Deep-Sea Research Part I: Oceanographic Research Papers 37: 1773-1782

Hecker, B. (1994) Unusual Megafaunal Assemblages on the Continental-Slope Off Cape-Hatteras. Deep-Sea Research Part II: Topical Studies in Oceanography 41: $809-834$

Heezen, B.C. \& Hollister, C.D. (1971) The Face of the Deep. Oxford University Press, London

Hersey, J.B. (1967) Deep-Sea Photography. John Hopkins Press, Baltimore

Jones, D.O.B., Bett, B.J. \& Tyler, P.A. (2007a) Depth-related changes in the arctic epibenthic megafaunal assemblages of Kangerdlugssuaq, East Greenland. Marine Biology Research 3: 191 - 204

Jones, D.O.B., Bett, B.J. \& Tyler, P.A. (2007b) Depth-related changes to density, diversity and structure of benthic megafaunal assemblages in the Fimbul ice shelf region, Weddell Sea, Antarctica Polar Biology 30: 1579-1592

Jones, D.O.B., Bett, B.J. \& Tyler, P.A. (2007c) Megabenthic ecology of the FaroeShetland Channel: a photographic study. Deep Sea Research Part I Oceanographic Research Papers 54: 1111-1128

Jones, D.O.B., Hudson, I.R. \& Bett, B.J. (2006) Effects of physical disturbance on the cold-water megafaunal communities of the Faroe-Shetland Channel. Marine Ecology Progress Series 319: 43-54

Kleinrock, M.C., Hey, R.N. \& Theberge, A.E. (1992) Practical Geological Comparison of Some Sea-Floor Survey Instruments. Geophysical Research Letters 19: 1407-1410

Klinkhammer, G.P., Chin, C.S., Keller, R.A., Dahlmann, A., Sahling, H., Sarthou, G., Petersen, S. \& Smith, F. (2001) Discovery of new hydrothermal vent sites in Bransfield Strait, Antarctica. Earth and Planetary Science Letters 193: 395407

Kohler, K.E. \& Gill, S.M. (2006) Coral Point Count with Excel extensions (CPCe): A Visual Basic program for the determination of coral and substrate coverage using random point count methodology. Computers and Geosciences 32: 1259-1269

Kollmann, H. \& Stachowitsch, M. (2001) Long-term changes in the benthos of the northern Adriatic Sea: A phototransect approach. Marine Ecology 22: 135-154

Lenth, R.V. (2001) Some practical guidelines for effective sample size determination. The American Statistician 55: 187-193

Leybourne, M.I. \& Vanwagoner, N.A. (1992) Volcanism, Age, and Hydrothermal Deposits of the West-Valley Segment, Juan-De-Fuca-Ridge. Canadian Journal of Earth Sciences 29: 2346-2352

Lonsdale, P. (1977a) Clustering of suspension feeding macrobenthos near abyssal hydrothermal vents at oceanic spreading centres. Deep-Sea Research 24: 857863

Lonsdale, P. (1977b) Deep-tow observations at the mounds abyssal thermal field, Galapagos Rift. Earth and Planetary Science Letters 36: 67-69

Machan, R. \& Fedra, K. (1975) A new towed underwater camera system for widerange benthic surveys. Marine Biology 33: 75-84 
Masson, D.G. (2001) Sedimentary processes shaping the eastern slope of the FaroeShetland Channel. Continental Shelf Research 21: 825-857

McConachy, T.F., Ballard, R.D., Mottl, M.J. \& Vonherzen, R.P. (1986) Geologic form and setting of a hydrothermal vent field at lat 10-degrees-56'N, East Pacific Rise - A detailed study using ANGUS and ALVIN. Geology 14: 295298

McHugh, C.M.G. \& Ryan, W.B.F. (2000) Sedimentary features associated with channel overbank flow: examples from the Monterey Fan. Marine Geology 163: $199-215$

Meier, O.W. \& Porter, J.W. (1991) Detecting change in coral reef communities: A comparison of survey methods. American Zoologist 31: 47A

Mortensen, P.B. \& Buhl-Mortensen, L. (2004) Distribution of deep-water gorgonian corals in relation to benthic habitat features in the Northeast Channel (Atlantic Canada). Marine Biology 144: 1223-1238

Normark, W.R., Hess, G.R., Stow, D.A.V. \& Bowen, A.J. (1980) Sediment waves on the Monterey Fan levee: a preliminary physical interpretation. Marine Geology 37: 1-18

Pilgrim, D.A., Parry, D.M., Jones, M.B. \& Kendall, M.A. (2000) ROV image scaling with laser spot patterns. Underwater Technology 24: 93-103

Pizarro, O. \& Singh, H. (2003) Toward large-area mosaicing for underwater scientific applications. IEEE Journal of Oceanic Engineering 28: 651-672

Ruhl, H.A. (2007) Abundance and size distribution dynamics of abyssal epibenthic megafauna in the northeast Pacific. Ecology 88: 1250-1262

Shortis, M.R. \& Harvey, E.S. (1998) Design and calibration of an underwater stereovideo system for the monitoring of marine fauna populations. International Archives Photogrammetry and Remote Sensing 32: 792-799

Shortis, M.R., Seager, J.W., Williams, A., Barker, B.A. \& Sherlock, M. (2007) A towed body stereo-video system for deep water benthic habitat surveys. In: Grun, A., Kahmen, H. (eds) Eighth Conference on Optical 3-D Measurement Techniques, ETH Zurich, Switzerland, pp 150-157

Singh, H., Adams, J., Mindell, D. \& Foley, B.P. (2000) Imaging Underwater for Archaeology. Journal of Field Archaeology 27: 319-328

Sokal, R.R. \& Rohlf, F.J. (1995) Biometry: the principles and practice of statistics in biological research. W. H. Freeman and Company, New York

Solan, M., Germano, J.D., Rhoads, D.C., Smith, C., Michaud, E., Parry, D., Wenzhofer, F., Kennedy, B., Henriques, C. \& Battle, E. (2002) Towards a greater understanding of pattern, scale and process in marine benthic systems: a picture is worth a thousand worms. Journal of Experimental Marine Biology and Ecology 285-286: 313-338

Starmans, A., Gutt, J. \& Arntz, W.E. (1999) Mega-epibenthic communities in Arctic and Antarctic shelf areas. Marine Biology 135: 269-280

Thurston, M.H., Bett, B.J., Rice, A.L. \& Jackson, P.A.B. (1994) Variations in the invertebrate abyssal megafauna in the North Atlantic Ocean. Deep-Sea Research Part I: Oceanographic Research Papers 41: 1321-1348

Tusting, R.F. \& Davis, D.L. (1992) Laser Systems and Structured Illumination for Quantitative Undersea Imaging. Marine Technology Society Journal 26: 5-12

Underwood, A.J. \& Chapman, M.G. (1998) Spatial analyses of intertidal assemblages on sheltered rocky shores. Australian Journal of Ecology 23: 138-157

Wakefield, W.W. \& Genin, A. (1987) The use of a Canadian (perspective) grid in deep-sea photography. Deep-Sea Research 34: 469-478 
Werner, F., Unsold, G., Koopman, B. \& Stefanon, A. (1980) Field observations and flume experiments on the nature of comet marks. Sedimentary Geology 26: 233-262

Wolf, P.R. (1983) Elements of Photogrammetry. McGraw-Hill, New York

Wynn, R.B., Masson, D.G. \& Bett, B.J. (2002) Hydrodynamic significance of variable ripple morphology across deep-water barchan dunes in the FaroeShetland Channel. Marine Geology 192: 309-319 


\section{FIGURES}

Figure 1: The National Oceanography Centre WASP vehicle, showing locations of A-altimeter, C-still camera, L-video lamps, B-batteries, V-video camera, M-monitor (acoustic telemetry) and F-flashgun.

Figure 2: Seabed disturbance from iceberg ploughing. Swath bathymetry showing clear iceberg plough marks, latitude and longitude indicated (A); mosaic of WASP seabed video covering approx. 30x3m of seafloor showing clear edge of ploughmark characterised by coarse sediment (B); WASP seafloor photographs covering approx. $3 \times 2 \mathrm{~m}$, examples of fine (C), intermediate (D) and coarse (E) sediment classifications

Figure 3: Changes in mean number of individuals in one photograph observed $(\mathrm{n}=$ 572) and expected and departure from expected (difference between observed and expected). The data were from shallow Faroe-Shetland Channel sites (FSC1-5; Bett 2001, Jones et al 2007). Error bars represent the standard deviation. 


\section{TABLES}

Table 1: Photographic vs. video counts of megafauna from WASP vehicle in Faroe-Shetland Channel example station (FSC1). Includes: Total megafaunal number $(\mathrm{N})$, number of taxa observed (S), Rarefied number of taxa $\left(\mathrm{ES}_{(300)}\right)$, Shannon-Wiener diversity index base e $\left(\mathrm{H}^{\prime}\right)$, Margalef diverisy index (d), Pielou evenness base e $\left(\mathrm{J}^{\prime}\right)$, Simpsons diversity index $\left(1-\lambda^{\prime}\right)$, Total faunal density (no ha $\left.{ }^{-1}\right)$, and area of seabed covered $\left(\mathrm{m}^{2}\right)$ by each method.

\begin{tabular}{|l|l|l|l|l|l|l|l|l|l|}
\hline & $\mathrm{N}$ & $\mathrm{S}$ & $\mathrm{ES}_{(300)}$ & $\mathrm{H}^{\prime}$ & $\mathrm{d}$ & $\mathrm{J}^{\prime}$ & $1-\lambda^{\prime}$ & Density $\left(\mathrm{no} \mathrm{ha}^{-1}\right)$ & Area covered \\
\hline Photo & 437 & 31 & 27.59 & 2.32 & 4.93 & 0.67 & 0.82 & 4215.44 & 1036.7 \\
\hline Video & 317 & 18 & 17.83 & 1.74 & 2.95 & 0.60 & 0.72 & 1676.61 & 1890.7 \\
\hline
\end{tabular}

Table 2: Appropriate approach for photograph studies focussed on specific deep-water applications

\begin{tabular}{|l|l|}
\hline Application & Approach \\
fiversity $>30$ organisms & photographs \\
$\mathrm{m}^{-2}$ & \\
\hline Faunal density / species & Photographs pooled to known area \\
diversity $<30$ organisms & \\
$\mathrm{m}^{-2}$ & \\
\hline Seabed geology & Single photographs \\
sedimentology & \\
\hline Geomorphology and & Mosaiced overlapping photographs / video \\
ecological & \\
dynamics & Single photographs or (preferably) mosaiced \\
\hline Distribution & \\
\hline
\end{tabular}

